\title{
Fortified Barrier Laser On The Vitreous Base In Vitrectomy For Rhegmatogenous Retinal Detachment
}

This article was published in the following Dove Press journal: Clinical Ophthalmology

\author{
Sun Ho Park (D) ${ }^{1,2}$ \\ Sang Cheol Yang ${ }^{1,2}$ \\ Jae Jung Lee (iD) ${ }^{1,2}$ \\ Hanjo Kwon ${ }^{1,2}$ \\ Sung Who Park (D) ${ }^{1,2}$ \\ Ji Eun Lee (iD) ${ }^{1,2}$ \\ 'Department of Ophthalmology, School \\ of Medicine, Pusan National University, \\ Yangsan, South Korea; ${ }^{2}$ Biomedical \\ Research Institute, Pusan National \\ University Hospital, Busan, South Korea
}

Purpose: To investigate the efficacy of fortified barrier laser (FBL) on the vitreous base in vitrectomy for rhegmatogenous retinal detachment (RRD).

Patients and methods: This was a retrospective study of patients who underwent vitrectomy for RRD without proliferative vitreoretinopathy. Barrier laser was applied as 3-4 rows surrounding the break at the end of fluid-air exchange. For the FBL, 3-4 rows of laser burn were additionally made about 0.5 clock-hour long adjacent to the break along the posterior border of the vitreous base. The primary outcome was single surgery success rate (SSSR) between two groups: FBL and conventional barrier laser (CBL) groups.

Results: Overall, 118 eyes were included; 50 eyes in the FBL group and 68 eyes in the CBL group. SSSR was $100 \%(50 / 50)$ in the FBL group and $91.2 \%(62 / 68)$ in the CBL group with a significant difference $(\mathrm{p}=0.038$ ). Four eyes of the recurrent cases in the CBL group were related to reopening of the break. All eyes achieved reattachment, and no differences were found in postoperative visual acuity at 6 months.

Conclusion: FBL on the vitreous base was efficacious in improving the anatomical success rate of vitrectomy.

Keywords: fortified barrier laser, vitreous base, rhegmatogenous retinal detachment, single surgery success rate, vitrectomy

\section{Summary Statement}

We introduced a modified barrier laser method fortified on the vitreous base in vitrectomy for rhegmatogenous retinal detachment. The traction force to the retina would be concentrated to the posterior border of the vitreous base, and thus the most common reason for treatment failure was insufficient laser placed around the anterior margin of the retinal break and residual vitreous base. Therefore, the new technique applied additional 3-4 rows of laser burn were additionally made about 0.5 clock-hour long adjacent to the break along the posterior border of the vitreous base. We investigated the single surgery success rate between our fortified barrier laser group and conventional barrier laser group. The recurrence rate was significantly lower comparing to the conventional method. So, we think that the modified barrier laser technique fortified along the vitreous base was a simple and effective procedure in PPV for RRD to reduce the recurrence rate without increasing the risk of specific complications related to photocoagulation.

\section{Introduction}

Since first introduced by Machemer in 1971, pars plana vitrectomy (PPV) has been shown to be an effective management option for rhegmatogenous retinal detachment
Correspondence: Jae Jung Lee Department of Ophthalmology, Pusan National University Hospital, 179 Gudeok-ro, Seo-gu, Busan 4924I, South Korea

Tel +82-5I-240-7957

Email jlee@pusan.ac.kr 
(RRD). ${ }^{1-3}$ Although scleral buckling is preferred in some specific situations, ${ }^{4,5}$ PPV is now generally accepted as the primary procedure for management of RRD. The most commonly used techniques consist of PPV, barrier laser photocoagulation, and the use of vitreous tamponade.

The goal of surgery for RRD is to achieve and maintain retinal reattachment by treating all retinal breaks and relieving the vitreous traction. Laser photocoagulation promotes rapid adhesion between the neurosensory retina and the retinal pigment epithelium and works as a barrier to prevent extension of subretinal fluid. ${ }^{6}$ Conventional laser photocoagulation technique involves two-to-three rows of laser burns being applied around each break and lattice degeneration. The strongest and most pathologically potent vitreoretinal traction occurs at the vitreous base. ${ }^{7,8}$ Therefore, the importance of vitreous base shaving was documented previously, ${ }^{9,10}$ and 360- degree peripheral laser retinopexy was advocated to produce a second ora serrata. ${ }^{11-16}$ However, intraoperative 360-degree peripheral laser retinopexy has several disadvantages, such as a prolonged operating time and potential overtreatment.

The traction force to the retina would be concentrated to the posterior border of the vitreous base, and thus the most common reason for treatment failure was insufficient laser placed around the anterior margin of the retinal break and residual vitreous base. ${ }^{17}$ Accordingly, if barrier laser is performed additionally on the vitreous base adjacent to the retinal break, the risk of the break reopening would be reduced, preventing recurrence as well as avoiding the drawbacks of 360- degree retinopexy.

In the present study, we introduced a modified barrier laser method fortified on the vitreous base, and investigated its efficacy by comparing the clinical results with the conventional method.

\section{Patients And Methods}

The current study was a retrospective, interventional, consecutive case series. The institutional review board of Pusan National University Hospital approved the study protocol (1901-002-074), and the requirement for informed consent was waived. The protocol complied with the tenets of the Declaration of Helsinki.

The medical records of patients who underwent PPV, endolaser photocoagulation, and gas tamponade for primary RRD consecutively between June 2011 and June 2018 were reviewed. The exclusion criteria were: combined scleral buckling, use of silicone oil tamponade, PVR of grade B or greater, retinal detachment due to a macular hole, bilateral RRD, no vision in the other eye, follow-up for less than 6 months, a history of intraocular surgery except for uncomplicated cataract removal, and other ocular disorders that may cause bias in the interpretation of the surgical outcomes.

All patients were operated on by the same surgeon (JE Lee), who used the Constellation (Alcon Laboratories Inc., Fort Worth, TX) sutureless 23-gauge (G) or 25-G vitrectomy system or EVA (DORC, Zuidland, The Netherlands) 25-G vitrectomy system and a non-contact wide-angle viewing system (Resight 700, Carl Zeiss Meditec AG, Jena, Germany). Phacoemulsification was performed concurrently at the surgeon's discretion. Triamcinolone acetonide was injected to confirm the presence of posterior vitreous detachment during the PPV, when required. As much of the vitreous was removed as possible with vitreous shaving. If visualization of the periphery was insufficient due to opacity or poor dilatation, the sclera was depressed in order to localize the retinal break and remove the vitreous. The flap of a horseshoe tear was removed with the vitreous cutter in most cases. A small break or both ends of a horseshoe tear were marked with endodiathermy. Heavy liquid was used only for bullous detachment and floppy retina. After the retina was flattened by fluid-air exchange, barrier laser was applied as follows.

The endolaser photocoagulation was performed using two different methods; fortified barrier laser (FBL) and conventional barrier laser $(\mathrm{CBL})$ in the respective groups. The FBL group underwent vitrectomy after July 2016, and the CBL group underwent vitrectomy between June 2011 and June 2016. In the CBL group, 3-4 rows of laser burns were made around each break at the end of fluid-air exchange. Lattice degeneration was also surrounded with barrier laser. In the FBL group, after applying barrier laser as the conventional method, 3-4 rows of laser burn were made additionally about 0.5 clock-hour long adjacent to the break along the posterior border of the vitreous base. As a result, the shape of the laser burns looked like an ocean sunfish (Mola mola [Linnaeus]) as shown in Figure 1. Tamponade was applied to all eyes using non-expansible gas (room air, $18 \% \mathrm{SF}_{6}$ or $12 \% \mathrm{C}_{3} \mathrm{~F}_{8}$ ) at the surgeon's discretion (Figures 2 and 3). In general, longer-acting gases were preferred for cases with an inferior break. Patients were requested to maintain a facedown posture for at least 1 day, regardless of the location of the break and the tamponade agent.

A comprehensive chart review was performed to document the clinical characteristics of each patient, including age, sex, preoperative and postoperative best-corrected 


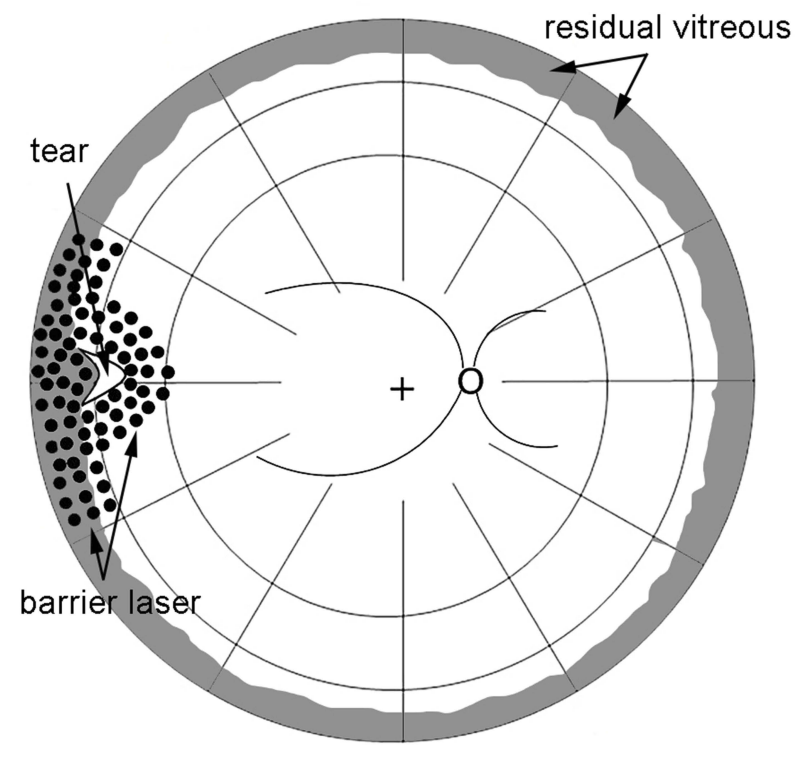

Figure I Diagram showing modified barrier laser around the retinal break and fortified along the vitreous base. visual acuity (BCVA), intraocular pressure (IOP), lens status, axial length, involvement of the macula, the number of retinal breaks, the range of retinal detachment, the presence of inferior breaks, symptom duration, the number of laser spots, and the type of tamponade gas. Snellen visual acuity measurements were converted to equivalent logarithm of the minimum angle resolution (LogMAR). An inferior break was defined as a break inside the retinal detachment located between the 4 o'clock and 8 o'clock positions.

The primary outcome measure was a difference in the single surgery success rate (SSSR) in the two groups, namely the FBL group versus the CBL group. SSSR was defined as the maintenance of the reattached retina for 3 months after a single operation without any additional procedure.

Descriptive statistics were used to analyze the data. The Mann-Whitney $U$-test was used to analyze the quantitative variables, and the Chi-squared test for independence or

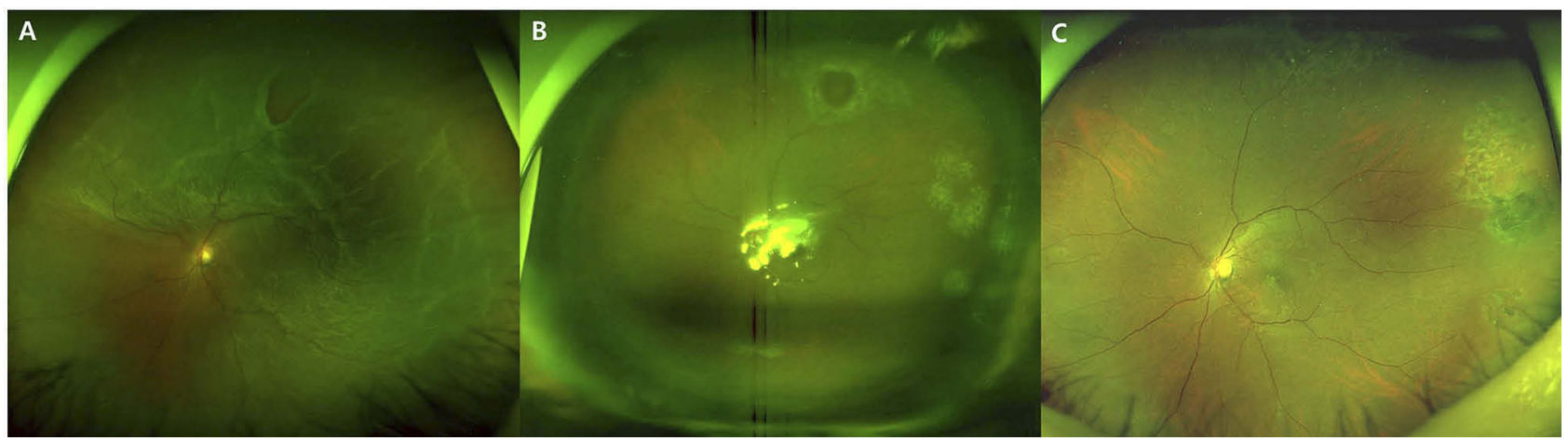

Figure 2 A case of fortified barrier laser for rhegmatogenous retinal detachment (RRD). (A) Ultra-wide field fundus photograph demonstrates RRD in 63-year-old woman with a horseshoe tear and a small atrophic hole. (B) Fortified barrier laser was performed during vitrectomy surrounding two breaks. The flap of the horseshoe tear was removed. (C) The retina was maintained attached after resolution of the tamponade gas.

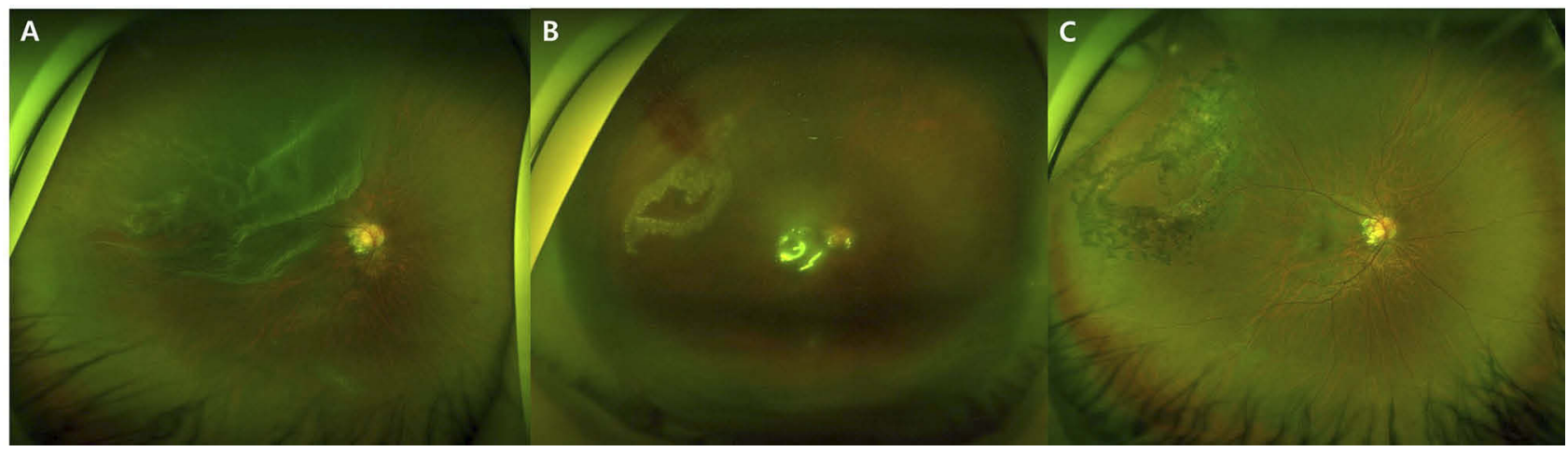

Figure $3 \mathrm{~A}$ case of fortified barrier laser for rhegmatogenous retinal detachment (RRD) caused by lattice degeneration. (A) Large tear with lattice degeneration is noted in ultra-wide field fundus photograph. (B) Barrier laser was performed surrounding the tear and lattice degeneration and was fortified along the posterior border of the vitreous base. (C) The reattachment of the retina was maintained after resorption of the gas. 
Fisher's exact test was used to analyze the categorical variables. A p-value of $<0.05$ was considered statistically significant. The Clopper-Pearson exact interval method was used to obtain the $95 \%$ confidence interval (CI). SPSS software (version 22) and Microsoft Excel were used for all statistical computations.

\section{Results}

In total, 118 eyes of 118 patients (59 men and 59 women, mean age of 56.2) were eligible for inclusion in the study. Of these, 50 were in the FBL group and 68 were in the CBL group. The FBL group comprised 22 men and 28 women with a mean age of 56.3 years, while the CBL group comprised 37 men and 31 women with a mean age of 56.2 years. There were no significant differences between two groups in relation to age, gender, preoperative BCVA and intraocular pressure, axial length, symptom duration, involvement of the macula, number of retinal breaks, range of retinal detachment, lens status, presence of inferior breaks, or number of laser shots except for the type of tamponade agent used (Table 1).

SSSR was $100 \%$ (50 of 50 eyes) in the FBL group (95\% CI; 92.9 100\%) and 91.2\% (62 of 68 eyes) in the CBL group (95\% CI; 81.8 96.7\%), with a significant difference between the groups $(\mathrm{p}=0.038)$. The difference of SSSR in 95\% CI was $0.1-16.0 \%$. Reattachment occurred finally in all cases in both the groups. The postoperative BCVA at 6 months was $\log$ MAR 0.15 in the FBL group and $\log$ MAR 0.17 in the CBL group, respectively, with no significant difference between two groups $(p=0.434)$ (Table 2$)$.
Table 3 summarizes the cases with re-detached retina in the CBL group. Four eyes of the recurrent cases had no other breaks found during the second operation, and the recurrence was related to reopening of the break in the primary operation. The other two eyes had a recurrence due to new retinal break development. Reattachment was achieved in all cases ultimately with 1.3 additional operations on average including a surgery for removing the silicone oil.

\section{Discussion}

The SSSR of the CBL group in the present study was comparable with those of $70-98 \%$ in previous studies; ${ }^{17-23} 4$ of the 6 recurrences were due to reopening of the primary break. In contrast, the SSSR was $100 \%(50 / 50)$ in the FBL group, who underwent modified barrier laser fortified on the vitreous base.

The condition of the vitreous in RRD is believed to be important by ophthalmologists unanimously. ${ }^{5}$ Traction to the retina caused by the anterior vitreous is the principal mechanism in the development of the retinal break, progression to retinal detachment and recurrence of RRD. Although vigorous removal of the vitreous is advocated by shaving the vitreous base, 9,10 it is practically impossible to remove the vitreous and its traction completely, as the anterior vitreous is attached firmly to the retina in the vitreous base. Accordingly, the residual peripheral vitreous after vitrectomy may apply persistent traction resulting in reopening of the original break or the formation of a new break usually along the posterior margin of the vitreous

Table I Demographics Of The Fortified And Conventional Barrier Laser Groups

\begin{tabular}{|l|l|l|l|}
\hline & FBL (\%) & CBL (\%) \\
\hline Number (total =II8) & 50 & 68 & P \\
Age (mean \pm SD), years & $56.30 \pm 8.58$ & $56.18 \pm 11.46$ & $37: 31$ \\
Gender(M:F) & $22: 28$ & $0.84 \pm 0.70$ & 0.885 \\
BCVA (mean \pm SD), logMAR & $0.70 \pm 0.62$ & $13.50 \pm 3.48$ & 0.264 \\
Intraocular pressure (mean \pm SD), mmHg & $13.74 \pm 2.94$ & $25.13 \pm 1.87$ & 0.315 \\
Axial length (mean \pm SD), mm & $25.58 \pm 2.18$ & $14.91 \pm 18.94$ & 0.677 \\
Duration (mean \pm SD), days & $14.96 \pm 26.21$ & $34: 34$ & 0.406 \\
Macula status (on:off) & $31: 19$ & $1.69 \pm 1.00$ & 0.154 \\
Number of retinal breaks (mean \pm SD) & $1.60 \pm 0.97$ & $4.26 \pm 1.46$ & 0.195 \\
Range of retinal detachment (mean \pm SD), hours & $3.84 \pm 2.00$ & $45: 23$ & 0.610 \\
Lens status (phakic:pseudophakic) & $39: 11$ & $21(30.9 \%)$ & 0.063 \\
Inferior break (n) & $10(20.0 \%)$ & $413.90 \pm 162.98$ \\
Number of laser spots (mean \pm SD) & $354.65 \pm 165.06$ & & 0.161 \\
Tamponade agent (n) & & $10: 42: 16$ & 0.210 \\
Air:SF $: C_{3} F_{8}$ & $45: 4: 1$ & 0.056 \\
\hline
\end{tabular}

Abbreviations: BCVA, best-corrected visual acuity; CBL, conventional barrier laser; FBL, fortified barrier laser. 
Table 2 Clinical Outcomes Of Primary Vitrectomy With Fortified And Conventional Barrier Laser For Rhegmatogenous Retinal Detachment

\begin{tabular}{|l|l|l|l|}
\hline & FBL (\%) & CBL (\%) & P \\
\hline Single surgery success rate & $50 / 50(100 \%)$ & $62 / 68(91.2 \%)$ & 0.038 \\
Final reattachment rate & $50 / 50(100 \%)$ & $68 / 68(100 \%)$ & 1.000 \\
BCVA at 6 months & $0.15 \pm 0.16$ & $0.17 \pm 0.18$ & 0.434 \\
\hline
\end{tabular}

Abbreviations: $\mathrm{BCVA}$, best-corrected visual acuity; $\mathrm{CBL}$, conventional barrier laser; FBL, fortified barrier laser.

base. ${ }^{24}$ In our 6 patients with re-detachments, this complication occurred in 4 eyes because of reopening of previous breaks, and in 2 eyes because of newly developed tears near the vitreous base. To prevent these problems, 360degree peripheral laser retinopexy was proposed. ${ }^{11}$

Several case series reported that 360-degree peripheral laser retinopexy was beneficial in improving the outcomes of RRD surgery. ${ }^{11-16}$ However, the technique has not been widely accepted as a routine procedure. It requires more operating time and is a potential overtreatment that incurs increased risk of complications related to laser photocoagulation, such as postoperative inflammation, formation of epiretinal membrane, ${ }^{25}$ and a tonic pupil. ${ }^{26}$ In addition, there is concern that a small quantity of subretinal fluid localized anterior to the barrier laser may be neglected in eyes that were treated with 360-degree peripheral laser retinopexy, and delayed detection of the recurrence would carry a risk of proliferative vitreoretinopathy.

Our technique of FBL on the vitreous base was developed to compensate for the weakness of 360-degree peripheral laser retinopexy. Traction to the retina around the retinal break is caused by the residual vitreous, which would be distributed circumferentially anterior to the break. In addition, as the vitreous is attached to the retina of the tear flap, the traction force would be concentrated at the circumferential ends of the horseshoe tear. In an attempt to cope with these problems, the FBL technique in the present study fortified the adhesion between the retina and retinal pigment epithelium along the posterior margin of the vitreous base adjacent to the break by applying photocoagulation in that area; as a measure of the success of this novel approach, the recurrence rate was significantly lower in the FBL group. The FBL technique appeared to have several advantages that reduce the surgical time, number of laser burns and related side effects compared to 360-degree barrier laser.

There was a significant difference between the two groups in terms of the tamponade agents used in our study. Long-acting non-expansible gases $\left(\mathrm{SF}_{6}, \mathrm{C}_{3} \mathrm{~F}_{8}\right)$ were used as the tamponade agents in the $\mathrm{CBL}$ group more frequently, whereas room air was used in most cases in the FBL group which included more recent operations. However, we reported that the use of air for tamponade in RRD was not inferior to that of perfluorinated gases in a previous study, ${ }^{27}$ although long-acting gas is, in general, expected to be more efficacious than room air in RRD. ${ }^{28}$ This fact suggests that the difference in the tamponade gas would not be a confounding factor that might result in a higher SSSR in the FBL group. Rather, use of the short-acting room air tamponade would have been encouraged by relying on the efficacy of the FBL procedure.

There were some limitations in our present study. First, there is the possibility of selection bias due to the retrospective nature of the study and the fact that the operations were performed at different periods for the two groups. However, the same instruments and similar techniques were used for both groups by the highly experienced single

Table 3 Summary Of Eyes With Recurrent Cases After Primary Vitrectomy For Rhegmatogenous Retinal Detachment

\begin{tabular}{|c|c|c|c|c|c|c|}
\hline $\begin{array}{l}\text { Patient } \\
\text { No. }\end{array}$ & $\begin{array}{l}\text { Tamponade In } \\
\text { Primary Surgery }\end{array}$ & $\begin{array}{l}\text { Time To } \\
\text { Recurrence (Days) }\end{array}$ & $\begin{array}{l}\text { Cause Of } \\
\text { Recurrence }\end{array}$ & Secondary Surgery & $\begin{array}{l}\text { Number Of } \\
\text { Additional Surgery }\end{array}$ & $\begin{array}{l}\text { BCVA } \\
\text { 6Mon }\end{array}$ \\
\hline I & $\mathrm{SF}_{6}$ & 30 & Reopening & PPV, endolaser, $\mathrm{SF}_{6}$ & I & $20 / 50$ \\
\hline 2 & Air & 21 & New tear & PPV, endolaser, $\mathrm{C}_{3} \mathrm{~F}_{8}$ & 1 & $20 / 60$ \\
\hline 3 & $\mathrm{C}_{3} \mathrm{~F}_{8}$ & 7 & Reopening & $\begin{array}{l}\text { PPV, encircling, } \\
\text { endolaser, } \\
\text { silicone oil }\end{array}$ & 2 & $20 / 40$ \\
\hline 4 & $\mathrm{SF}_{6}$ & 14 & Reopening & $\begin{array}{l}\text { PPV, endolaser, } \\
\text { Silicone oil }\end{array}$ & 2 & $20 / 100$ \\
\hline 5 & $\mathrm{SF}_{6}$ & 50 & New tear & PPV, endolaser, $\mathrm{SF}_{6}$ & I & $20 / 25$ \\
\hline 6 & $\mathrm{SF}_{6}$ & 20 & Reopening & PPV, endolaser, $\mathrm{C}_{3} \mathrm{~F}_{8}$ & I & $20 / 50$ \\
\hline
\end{tabular}

Abbreviation: PPV, pars plana vitrectomy. 
surgeon, which would minimize selection and surgeon bias. Second, the operation time was not compared between the two groups. However, considering that there were no significant differences between the two groups in total laser spots, it is unlikely that the FBL procedure took significantly longer. On the contrary, more frequent use of tamponade using perfluorinated gases in the CBL group, which involved extra time for preparation and infusion of the gas, probably increased the operation time in that group. Third, the current study included only simple RRD cases, and cases with vitreoretinal proliferative membrane or cases treated with combined scleral buckling were excluded. And, in our result, six eyes were re-detached in the CBL group. But, two eyes had a recurrence due to a new retinal tear and these cases may seem unrelated to our new laser technique. These new tear can be caused by another factors other than the primary laser technique. However, these cases were included because SSSR was compared according to the operation period and the laser technique, so there is the possibility of bias. The current results should be interpreted in the light of these limitations; therefore, a future study is needed to validate our results.

In conclusion, the modified barrier laser technique fortified along the vitreous base was a simple and effective procedure in PPV for RRD to reduce the recurrence rate without increasing the risk of specific complications related to photocoagulation.

\section{Acknowledgments}

This paper was presented at the 2019 European VitreoRetinal Society (EVRS) congress and 2019 The Association for Research in Vision and Ophthalmology (ARVO) as a poster presentation.

\section{Disclosure}

Lee JE reports consultant fees, honoraria and research funds from Bayer; honoraria and research funds from Novartis; consultant fees and honoraria from Alergan, honoraria from Alcon; and consultant fees and honoraria from Abbvie. The authors report no other conflicts of interest in this work.

\section{References}

1. Machemer R, Buettner H, Norton EW, Parel JM. Vitrectomy: a pars plana approach. Trans Am Acad Ophthalmol Otolaryngol. 1971;75:813-820.

2. SPR Study Group. View 2: the case for primary vitrectomy. $\mathrm{Br} J$ Ophthalmol. 2003;87:784-787. doi:10.1136/bjo.87.6.784
3. Schwartz SG, Flynn HW. Primary retinal detachment: scleral buckle or pars plana vitrectomy? Curr Opin Ophthalmol. 2006;17:245-250. doi:10.1097/01.icu.0000193097.28798.fc

4. Park SW, Kwon HJ, Byon IS, Lee JE, Oum BS. Impact of age on scleral buckling surgery for rhegmatogenous retinal detachment. Kor J Ophthalmol. 2017;31:328-335. doi:10.3341/kjo.2016.0024

5. Park SW, Lee JJ, Lee JE. Scleral buckling in the management of rhegmatogenous retinal detachment: patient selection and perspectives. Clin Ophthalmol. 2018;12:1605-1615. doi:10.2147/OPTH. S153717

6. Folk JC, Sneed SR, Folberg R, Coonan P, Pulido JS. Early retinal adhesion from laser photocoagulation. Ophthalmology. 1989;96:1523-1525. doi:10.1016/s0161-6420(89)32696-0

7. Choudhary MM, Choudhary MM, Saeed MU, Ali A. Removal of silicone oil: prognostic factors and incidence of retinal redetachment. Retina. 2012;32:2034-2038. doi:10.1097/IAE.0b013e3182562045

8. Jonas JB, Knorr HL, Rank RM, Budde WM. Retinal redetachment after removal of intraocular silicone oil tamponade. Br J Ophthalmol. 2001;85:1203-1207. doi:10.1136/bjo.85.10.1203

9. Martínez-Castillo V, Zapata MA, Boixadera A, Fonollosa A, García-Arumí J. Pars plana vitrectomy, laser retinopexy, and aqueous tamponade for pseudophakic rhegmatogenous retinal detachment. Ophthalmology. 2007;114:297-302. doi:10.1016/j. ophtha.2006.07.037

10. Oyagi T, Emi K. Vitrectomy without scleral buckling for proliferative vitreoretinopathy. Retina. 2004;24:215-218. doi:10.1097/00006982200404000-00004

11. Hoffman ME, Sorr EM. Management of giant retinal tears without scleral buckling. Retina. 1986;6:197-204. doi:10.1097/00006982198606040-00001

12. Avitabile T, Longo A, Lentini G, Reibaldi A. Retinal detachment after silicone oil removal is prevented by 360 degrees laser treatment. Br J Ophthalmol. 2008;92:1479-1482. doi:10.1136/bjo.2008.140087

13. Iwase T, Jo YJ, Oveson BC. Effect of prophylactic $360^{\circ}$ laser treatment for prevention of retinal detachment after phacovitrectomy: (Prophylactic $360^{\circ}$ laser treatment for prevention of retinal detachment). BMC Ophthalmol. 2013;13:77. doi:10.1186/14712415-13-48

14. Koh HJ, Cheng L, Kosobucki B, Freeman WR. Prophylactic intraoperative 360 degrees laser retinopexy for prevention of retinal detachment. Retina. 2007;27:744-749. doi:10.1097/ IAE.0b013e318030ebd7

15. Dabour SA. The outcome of surgical management for giant retinal tear more than 180-. BMC Ophthalmol. 2014;14:86. doi:10.1186/ 1471-2415-14-86

16. Ambresin A, Wolfensberger TJ, Bovey EH. Management of giant retinal tears with vitrectomy, internal tamponade, and peripheral 360 degrees retinal photocoagulation. Retina. 2003;23:622-628. doi:10.1097/00006982-200310000-00003

17. Heimann H, Zou X, Jandeck C, et al. Primary vitrectomy for rhegmatogenous retinal detachment: an analysis of 512 cases. Graefes Arch Clin Exp Ophthalmol. 2006;244:69-78. doi:10.1007/s00417005-0026-3

18. Mendrinos E, Dang-Burgener NP, Stangos AN, Sommerhalder J, Pournaras CJ. Primary vitrectomy without scleral buckling for pseudophakic rhegmatogenous retinal detachment. Am J Ophthalmol. 2008;28:1063-1070. doi:10.1016/j.ajo.2008.01.018

19. Lai MM, Ruby AJ, Sarrafizadeh R, et al. Repair of primary rhegmatogenous retinal detachment using 25 -gauge transconjunctival sutureless vitrectomy. Retina. 2008;28:729-734. doi:10.1097/ IAE.0b013e318162b01c

20. Dugas B, Lafontaine PO, Guillaubey A, et al. The learning curve for primary vitrectomy without scleral buckling for pseudophakic retinal detachment. Graefes Arch Clin Exp Ophthalmol. 2009;247:319-324. doi:10.1007/s00417-008-0997-y 
21. Hakin KN, Lavin MJ, Leaver PK. Primary vitrectomy for rhegmatogenous retinal detachment. Graefes Arch Clin Exp Ophthalmol. 1993;231:344-346. doi:10.1007/bf00919031

22. Escoffery RF, Olk RJ, Grand MG, Boniuk I. Vitrectomy without scleral buckling for primary rhegmatogenous retinal detachment. Am J Ophthalmol. 1985;99:275-281. doi:10.1016/0002-9394(85) 90356-3

23. Azad RV, Chanana B, Sharma YR, Vohra R. Primary vitrectomy versus conventional retinal detachment surgery in phakic rhegmatogenous retinal detachment. Acta Ophthalmol Scand. 2007;85:540 545. doi:10.1111/j.1600-0420.2007.00888.x

24. Kreiger AE. Wound complications in pars plana vitrectomy. Retina. 1993;13:335-344. doi:10.1097/00006982-199313040-00012
25. Mester U, Volker B, Kroll P, Berg P. Complications of prophylactic argon laser treatment of retinal breaks and degenerations in 2,000 eyes. Ophthalmic Surg. 1988;19:482-484.

26. Yilmaz I, Perente I, Saracoglu B, Yazici AT, Taskapili M. Changes in pupil size following panretinal retinal photocoagulation: conventional laser vs pattern scan laser (PASCAL). Eye (Lond). 2016;30:13591364. doi: $10.1038 /$ eye.2016.135

27. Pak KY, Lee SJ, Kwon HJ, et al. Exclusive use of air as gas tamponade in rhegmatogenous retinal detachment. J Ophthalmol. 2017;2017:1341948

28. Tan HS, Oberstein SY, Mura M, Bijl HM. Air versus gas tamponade in retinal detachment surgery. Br J Ophthalmol. 2013;97:80-82. doi:10.1136/bjophthalmol-2012-302140
Clinical Ophthalmology

\section{Publish your work in this journal}

Clinical Ophthalmology is an international, peer-reviewed journal covering all subspecialties within ophthalmology. Key topics include: Optometry; Visual science; Pharmacology and drug therapy in eye diseases; Basic Sciences; Primary and Secondary eye care; Patient Safety and Quality of Care Improvements. This journal is indexed on PubMed

Submit your manuscript here: https://www.dovepress.com/clinical-ophthalmology-journal
Dovepress

Central and CAS, and is the official journal of The Society of Clinical Ophthalmology (SCO). The manuscript management system is completely online and includes a very quick and fair peer-review system, which is all easy to use. Visit http://www.dovepress.com/ testimonials.php to read real quotes from published authors. 